\title{
O estresse salino retarda o desenvolvimento morfofisiológico e a ativação de galactosidases de parede celular em caules de Vigna unguiculata
}

Fabrício Bonfim Sudério ${ }^{1}$, Gislainy Karla da Costa Barbosa² ${ }^{2}$ Enéas Gomes-Filho² e Joaquim Enéas-Filho ${ }^{2,3}$

Recebido em 12/12/2008. Aceito em 3/12/2010

\begin{abstract}
RESUMO
(O estresse salino retarda o desenvolvimento morfofisiológico e a ativação de galactosidases de parede celular em caules de Vigna unguiculata). Com o objetivo de examinar o envolvimento das $\alpha$ - e $\beta$-galactosidases na expansão celular de caules de plântulas de feijão-de-corda submetidas a estresse salino durante o estabelecimento da plântula, e de analisar os efeitos do estresse salino no desenvolvimento das plântulas e nas atividades enzimáticas, sementes de feijão-de-corda Pitiúba foram semeadas em água destilada e em solução de $\mathrm{NaCl} 100 \mathrm{mM}$. Foram coletados caules em diferentes estádios de desenvolvimento e com diferentes tempos após a semeadura. Avaliou-se o crescimento através das medidas de comprimento e das matérias fresca e seca dos caules. A salinidade tanto inibiu como retardou o crescimento dos caules. Os efeitos do $\mathrm{NaCl}$ nas atividades galactosidásicas de parede celular foram estudados in vivo e in vitro. A inibição e o retardamento do crescimento dos caules correlacionaram-se com as variações em atividades galactosidásicas. As galactosidases de parede celular de caules de plântulas tiveram suas atividades inibidas com o aumento da concentração de sal no meio de reação. A partir de $250 \mathrm{mM}$ de $\mathrm{NaCl}$ as $\beta$-galactosidases foram mais sensíveis ao sal que as $\alpha$-galactosidases.
\end{abstract}

Palavras-chave: desenvolvimento, feijão-de-corda, galactosidases, salinidade

\begin{abstract}
(Salt stress delays morphophysiological development and activation of cell wall galactosidases in Vigna unguiculata stems). In order to examine the participation of $\alpha$ - and $\beta$-galactosidases in the cell expansion of stems from cowpea seedlings submitted to salt stress during plant establishment as well as to analyze the effect of salt stress on the development of seedlings and enzymatic activities, Pitiúba cowpea seeds were sown in distilled water and in $100 \mathrm{mM} \mathrm{NaCl}$. Throughout seed germination and seedling development, stems were harvested from seedlings at different stages of development and at different times after planting. Growth was evaluated by measuring stem length and fresh and dry mass of stems. Salinity both inhibited and delayed the growth of seedling stems. The effects of $\mathrm{NaCl}$ on galactosidase activities of the cell wall were studied, both in vivo and in vitro. Galactosidase activities in vivo were related to effects of $\mathrm{NaCl}$ inhibition and delay of stem development. The increase in salt concentration inhibited isolated galactosidase activity of cell wall from stems of seedlings. Starting at $250 \mathrm{mM} \mathrm{NaCl}, \beta$-galactosidases were more sensitive to salt than $\alpha$-galactosidases.
\end{abstract}

Key words: development, cowpea, galactosidases, salinity

\section{Introdução}

A salinidade é um importante estresse abiótico que afeta a produção agrícola em várias regiões do globo terrestre, e tem sido em grande parte, agravada por práticas agrícolas inadequadas, especialmente aquelas associadas com a agricultura irrigada (Chinnusamy et al. 2005). De modo geral, os maiores problemas de salinidade no mundo estão nas regiões áridas e semi-áridas. O Nordeste do Brasil é a região onde a agricul- tura é mais gravemente afetada pelo problema da salinidade. É no semi-árido nordestino, onde a salinidade associada a áreas intensamente cultivadas sob condições de irrigação que o problema passa a ter relevância econômica (Gheyi, 2000).

A redução no crescimento das plantas causada pelo estresse salino se deve aos efeitos osmóticos e tóxicos do excesso de sais no ambiente radicular, o qual pode levar a um desbalanceamento nutricional e afetar processos fisiológicos relevantes para o crescimento e desenvolvimento

\footnotetext{
Universidade Estadual do Ceará, Faculdade de Educação de Crateús, Crateús, CE, Brasil

2 Universidade Federal do Ceará, Departamento de Bioquímica e Biologia Molecular, Fortaleza, CE, Brasil

3 Autor para correspondência: joaquime@ufc.br
} 
das plantas (Zhu 2001; Tester \& Davenport 2003; Parida \& Das 2005). Apesar de bastante estudados, os mecanismos pelos quais a salinidade afeta o metabolismo vegetal, reduzindo deste modo o crescimento e o desenvolvimento das plantas, ainda não são completamente entendidos. $O$ fato de muitos estudos envolvendo salinidade serem realizados levando-se em conta apenas o tempo após a aplicação do estresse - idade cronológica - faz com que não se conheça ao certo se a redução observada no crescimento se deve apenas a retardamento ou inibição no crescimento e desenvolvimento das plantas. Os resultados de alguns estudos, quando analisados em função do tempo após a semeadura, mostram que em várias espécies vegetais a salinidade retarda e/ou inibe o crescimento da planta (Zeng et al. 2001; Wang et al. 2001; Chartzoulakis et al. 2002; Martínez-Ballesta et al. 2004; Sosa et al. 2005). Segundo Sousa et al. (2004), esse problema pode ser evitado se as respostas à salinidade forem analisadas com plantas controle e estressadas nos mesmos estádios de desenvolvimento morfofisiológico.

$\mathrm{Na}$ fase de estabelecimento da plântula, a salinidade pode retardar e/ou inibir o crescimento porque inibe, não apenas a mobilização das reservas da semente (Bewley \& Black 1994; Enéas-Filho et al. 1995), mas também o alongamento celular (Taiz \& Zeiger 2004). O processo de alongamento celular e o conseqüente crescimento da planta ocorrem, em grande parte, devido à ação de enzimas associadas às paredes celulares que são responsáveis pela autólise e afrouxamento das mesmas. As $\alpha$ - e $\beta$-galactosidases, dentre outras enzimas, são conhecidas por atuarem nos componentes da parede celular, promovendo o seu afrouxamento e daí o alongamento celular (Alcântara et al. 1999; Barnavon et al. 2000). Embora existam algumas informações sobre os efeitos da salinidade nas atividades das $\alpha$ - e $\beta$ - galactosidases citosólicas (GonzalesMurua et al. 1985; Corchete \& Guerra 1986; Enéas-Filho et al. 1995), pouco se conhece sobre os efeitos do estresse salino nas atividades galactosidásicas de parede celular.

Portanto, os objetivos deste trabalho foram analisar os efeitos da salinidade in vivo e in vitro nas atividades $\alpha$ - e $\beta$-galactosidásicas de caules de plântulas de feijão-de-corda [Vigna unguiculata (L.) Walp.], durante a fase de estabelecimento, para verificar o possível envolvimento dessas enzimas na inibição da expansão celular.

\section{Material e métodos}

\section{Material vegetal, condições de germinação e coleta}

Foram utilizadas sementes de feijão-de-corda [Vigna unguiculata (L.) Walp.], cultivar Pitiúba, provenientes do Centro de Ciências Agrárias da Universidade Federal do Ceará, Campus do Pici, Ceará - Brasil. Após serem limpas, as sementes foram selecionadas e tratadas com uma solução de hipoclorito de sódio, contendo 0,5\% de cloro ativo, por cinco minutos (Gomes-Filho \& Prisco, 1978), e semeadas em folhas de papel de filtro embebidas com água destilada (tratamento controle) ou com solução de $\mathrm{NaCl} 100 \mathrm{mM}$ (tratamento salino), sob fotoperíodo de $12 \mathrm{~h}$, irradiância de $16 \mu \mathrm{mol} \mathrm{m}^{-2} \mathrm{~s}^{-1}$, temperatura de $25 \pm 2{ }^{\circ} \mathrm{C}$ e umidade relativa próxima a $100 \%$. Após a semeadura, as plântulas foram selecionadas e coletadas nos seguintes estádios de desenvolvimento (ED): ED III - radícula maior que $2 \mathrm{~cm}$ e menor que $5 \mathrm{~cm}$, hipocótilo no interior do papel; ED IV - radícula maior que $5 \mathrm{~cm}$, hipocótilo no interior do papel; ED V - radícula maior que $5 \mathrm{~cm}$, hipocótilo saindo do papel; ED VI - radícula maior que $5 \mathrm{~cm}$, cotilédones fora do papel, hipocótilo curvo e folhas cotiledonares não abertas; ED VII - radícula maior que $5 \mathrm{~cm}$, cotilédones fora do papel, hipocótilo reto e folhas cotiledonares não abertas; e ED VIII - radícula maior que $5 \mathrm{~cm}$, cotilédones fora do papel, hipocótilo reto e folhas cotiledonares abertas, conforme Sousa et al. (2004). Também foram coletadas plântulas aos três, cinco, sete e nove dias após a semeadura em condições controle e de estresse salino.

\section{Determinações do comprimento e das matérias fresca e seca}

As plântulas foram coletadas, sendo os caules separados dos outros órgãos em três grupos, cada um contendo 50 caules de plântulas do mesmo tratamento e na mesma fase (estádio de desenvolvimento ou dias após a semeadura). Em seguida, foram feitas as determinações dos comprimentos e das matérias fresca e seca dos caules provenientes de plântulas nos ED III, IV, V, VI, VII e VIII e nos dias três, cinco, sete e nove após a semeadura em condições controle e de salinidade. A determinação da matéria fresca foi feita através da pesagem dos caules logo após a coleta, os quais, em seguida foram congelados. A matéria seca foi obtida após liofilização por um tempo suficiente para os caules atingirem massa constante. Posteriormente, os caules liofilizados foram pesados, macerados, acondicionados em frascos de vidro e armazenados à temperatura de aproximadamente $10{ }^{\circ} \mathrm{C}$, até posterior utilização.

\section{Extração de proteínas ionicamente ligadas à parede}

Três grupos de 25 caules liofilizados de plântulas nos ED III ao ED VIII e nos dias três, cinco, sete e nove após a semeadura foram utilizados para a obtenção de paredes celulares. Para isso, os caules foram macerados em tampão citrato de sódio $25 \mathrm{mM}$ - fosfato de potássio $50 \mathrm{mM} \mathrm{pH} \mathrm{5,5} \mathrm{acrescido}$ de polivinil polipirrolidona (PVP) $0,1 \%(\mathrm{~m} / \mathrm{v})$, na proporção de 1:50 (peso/volume), durante uma hora em banho de gelo. Após centrifugação, o precipitado resultante foi utilizado para a obtenção da parede celular. Em seguida, estas paredes celulares foram usadas para a extração das proteínas associadas de forma iônica a elas. Estes procedimentos foram realizados de acordo com a metodologia de Seara et al. (1988).

\section{Determinação da pureza da preparação de parede celular}

A pureza da preparação de parede celular foi testada determinando-se a possível presença das enzimas desidrogenase da glucose-6-fosfato (citosólica) e da fosfatase ácida vacuolar. A atividade da desidrogenase da glucose-6-fosfato 
foi determinada de acordo com Molina et al. (2003) e a atividade da fosfatase ácida vacuolar foi determinada de acordo com o método de Granjeiro et al. (2003).

\section{Determinações das atividades $\alpha$-e $\beta$-galactosidásicas e do teor de proteína}

A atividade $\alpha$-galactosidásica de parede celular foi determinada de acordo com o método de Dey \& Pridham (1969), enquanto que a atividade $\beta$-galactosidásica foi realizada de acordo com Kanfer et al. (1973), com modificações feitas por Enéas-Filho et al. (1995). A mistura de reação foi composta de $0,5 \mathrm{~mL}$ de extrato e $0,5 \mathrm{~mL}$ do substrato sintético $\mathrm{p}$-nitrofenil- $\alpha$-D-galactopiranosídeo ou p-nitrofenil- $\beta$-D-galactopiranosídeo dissolvidos em tampão citrato a $25 \mathrm{mM}$ - fosfato a $50 \mathrm{mM}, \mathrm{pH}$ 5,0 (para $\alpha$-galactosidase) ou pH 4,0 (para $\beta$-galactosidase). Após 15 minutos a $60^{\circ} \mathrm{C}$, a reação foi interrompida pela adição de $1,5 \mathrm{~mL}$ de carbonato de sódio a $0,1 \mathrm{M}$. A atividade enzimática foi determinada pela quantidade de produto formado, medindo-se a absorbância em $400 \mathrm{~nm}\left(\mathrm{~A}_{400}\right)$ e subtraindose de cada leitura o valor de absorbância $\left(\mathrm{A}_{400}\right)$ da prova em branco. As diferenças em absorbâncias $\left(\Delta \mathrm{A}_{400}\right)$ foram transformadas em unidades de atividade (UA), sendo uma UA correspondente a uma $\Delta \mathrm{A}_{400}$ de 0,01 . A concentração de proteína nos extratos foi determinada de acordo com Bradford (1976), tendo a albumina sérica bovina como padrão. Para as determinações de concentração de proteína e de atividade enzimática foram utilizados três extratos (repetições), sendo cada um dosado em triplicata.

\section{Efeito do $\mathrm{NaCl}$, in vitro, nas atividades galactosidásicas}

A metodologia de extração de $\alpha$ - e $\beta$-galactosidases associadas à parede celular foi a mesma descrita no item anterior. As atividades das enzimas foram determinadas em função de quantidades crescentes de $\mathrm{NaCl}$ no meio de reação $(50,100,250,500,750$ e $1000 \mathrm{mM})$. Os valores de atividades enzimáticas foram expressos em percentagens do controle (meio de reação sem $\mathrm{NaCl}$ ) e corresponderam à média de três repetições, cada uma em triplicata.

\section{Resultados e discussão}

O comprimento dos caules aumentou do ED III ao ED VIII, tanto em condições controle como no tratamento salino. Apesar de ter havido interseções entre os desvios padrão, pode-se afirmar, com base nos valores médios, que houve uma tendência para o comprimento dos caules do tratamento salino ser inferior àquele do controle. Ao analisar-se o crescimento em função do tempo após a semeadura, o comprimento dos caules aumentou em ambos os tratamentos, porém sob condições salinas houve uma forte redução no comprimento dos caules, sendo em média $31,2 \%$ menor que o controle no nono dia de crescimento (Fig. 1B).

Observou-se, também, que a matéria fresca dos caules aumentou do ED III ao VIII, tanto nas condições controle como no tratamento salino, porém os valores no tratamento salino foram sempre inferiores, em média, $21,4 \%$ àqueles do controle, exceto no ED VIII, quando foram iguais (Fig. 1C). A matéria fresca quando analisada em função do tempo de semeadura, foi crescente do $3^{\circ}$ ao $9^{\circ}$ dia, porém, esses valores para os caules oriundos do tratamento salino foram inferiores àqueles do controle, atingindo no $9^{\circ}$ dia, um valor $34,4 \%$ menor (Fig. 1D).

A matéria seca dos caules aumentou, no tratamento salino, durante todo o período experimental. No tratamento controle aumentou do ED III ao VII, permanecendo com valor constante do ED VII ao ED VIII. Em condições de estresse salino, a matéria seca foi sempre menor ou igual àquela do controle até o ED VII. Contudo, no ED VIII houve um aumento na matéria seca média dos caules do tratamento salino de $29,4 \%$, quando comparado àquela do controle (Fig. 1E). Este resultado, juntamente com aqueles dos comprimentos dos caules, que em condições salinas mostraram tendência de redução em relação ao controle, sugere que, sob estresse salino, há um espessamento dos caules, possivelmente devido a uma maior expansão das paredes celulares (Chen et al. 1999). Quando o crescimento foi analisado em função do tempo após a semeadura, observou-se que a matéria seca no tratamento controle aumentou até o $7^{\circ}$ dia, quando se estabilizou, enquanto que no tratamento salino ela aumentou lentamente até o 70 dia e mais rapidamente até o final do período experimental, porém foi sempre inferior àquela do controle (Fig. $1 \mathrm{~F}$ ).

Os resultados apresentados na Fig. 1 demonstram claramente que o $\mathrm{NaCl}$ a $100 \mathrm{mM}$ reduziu drasticamente o crescimento dos caules, quando analisado em função da idade cronológica, e muito pouco, quando analisado em função do estádio de desenvolvimento. Isto demonstra que o sal causou grande retardamento, porém pequena inibição no crescimento e desenvolvimento das plântulas de feijão-de-corda. Estes resultados também reforçam a necessidade de que estudos sobre estresse salino sejam também analisados levando-se em conta o desenvolvimento morfofisiológico das plântulas (Sousa et al. 2004). De modo geral, os resultados aqui apresentados foram similares aos observados por outros autores (Jolivet et al. 1990, em Triticum aestivum; Lutts et al. 1995, em Oryza sativa; Kurban et al. 1998, em Vigna radiata; Lovato et al. 1999, em Stylosanthes humilis; Ruiz et al. 1999, em Citrus aurantium).

Para se certificar que o extrato contendo as proteínas associadas à parede celular, não estava contaminado com proteínas citosólicas e de vacúolos em quantidade que comprometesse a confiabilidade do processo de extração, foram feitas medidas das atividades das enzimas desidrogenase da glucose-6-fosfato e fosfatase ácida nos extratos citosólico e de parede celular. Após as determinações, verificou-se que não havia atividade da desidrogenase da glucose-6-fosfato no extrato de parede celular e que o percentual de atividade da fosfatase ácida representava apenas $4,6 \%$ da atividade total determinada no extrato citosólico, estando dentro do limite aceitável. Este mesmo procedimento foi utilizado por Gómez 


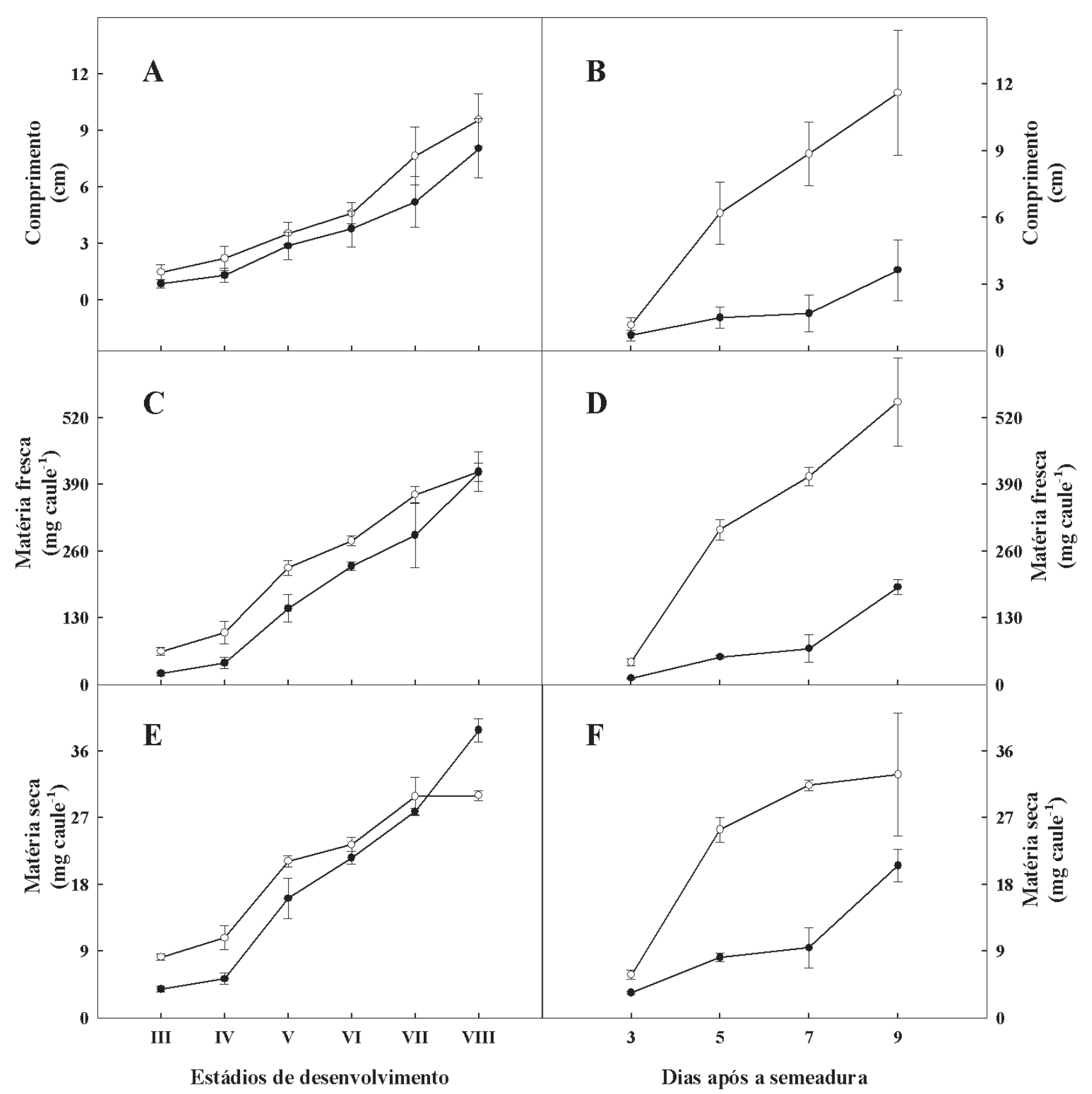

Figura 1. Comprimento (A e B), matérias fresca (C e D) e seca (E e F) dos caules de plântulas de feijão-de-corda [Vigna unguiculata (L.) Walp.] cultivar Pitiúba em função do estádio de desenvolvimento ( $\mathrm{A}, \mathrm{C}$ e E) e do tempo após a semeadura (B, D e F) em água destilada (tratamento controle, o-o) e em solução de NaCl a $100 \mathrm{mM}$ (tratamento salino, $\bullet-\bullet)$.

et al. (1995) para garantir que o fluido extracelular de células de hipocótilos de feijão-de-corda não estava contaminado com proteínas citoplasmáticas, o que permitiu obter um fluido extracelular com apenas 1,5 e 1,4\% de contaminação com proteínas citosólicas e vacuolares, respectivamente.

As atividades $\alpha$ - e $\beta$-galactosidásicas de parede celular medidas em função dos estádios de desenvolvimento morfofisiológico variaram de acordo com os tratamentos (Fig. 2A, C). A atividade $\alpha$-galactosidásica no tratamento controle, aumentou com o desenvolvimento da plântula até o ED VI, permanecendo constante até o ED VIII. No tratamento salino, houve um pequeno aumento de atividade até o ED V, seguido de um aumento acentuado até o ED VI, para, em seguida, crescer lentamente até o ED VIII. Convém salientar, que até o ED V a atividade $\alpha$-galactosidásica no controle foi sempre superior àquela do tratamento salino, enquanto que, do ED VI ao ED VIII ocorreu o oposto (Fig. $2 \mathrm{~A})$. As variações em atividade $\beta$-galactosidásica de parede celular em função do estádio de desenvolvimento mostraram que, no tratamento controle, ela aumentou até o ED 
$\mathrm{V}$, decresceu até o ED VII, quando aumentou novamente até o ED VIII (Fig. 2B). Já no tratamento salino houve um aumento progressivo nesta atividade, durante todo o período experimental. Do mesmo modo que a atividade da $\alpha$-galactosidase, os valores de atividade $\beta$-galactosidásica foram maiores no controle do que no tratamento salino, até o ED V, iguais no ED VI e após este estádio observou-se a inversão desta atividade enzimática (Fig. 2C). Quando analisadas em função do tempo de semeadura, as atividades $\alpha$ - e $\beta$-galactosidásicas dos tratamentos controle aumentaram até o final do período experimental. Além disso, observou-se que o estresse salino retardou as atividades $\alpha$ - e $\beta$-galactosidásicas de parede celular ou afetou diretamente a expressão gênica dessas enzimas (Fig. 2B, D).

Quando os teores de proteínas foram expressos em função do estádio de desenvolvimento, observou-se que, no tratamento salino, foram menores do que no controle até o ED V, mas a partir do ED VI, eles superaram os do controle (Fig. 2E). Quando estes teores foram expressos em função do tempo de semeadura, foram menores no tratamento salino do que no controle até o $5^{\circ}$ dia. Porém, após o $7^{\circ}$ dia, foram maiores, superando, no $9^{\circ}$ dia, os valores do tratamento controle em cerca de 50\% (Fig. 2F).

As atividades $\alpha$ - e $\beta$-galactosidásicas de parede celular de caules de feijão-de-corda permaneceram estáveis até a concentração de $100 \mathrm{mM}$ de $\mathrm{NaCl}$ no meio de reação (in vitro). No entanto, acima dessa concentração a atividade da $\beta$-galactosidase decresceu rapidamente, enquanto o decréscimo na atividade $\alpha$-galactosidásica foi menos acentuado, de modo que na presença de $1.000 \mathrm{mM}$ de $\mathrm{NaCl}$ as atividades destas enzimas foram inibidas em $64 \%$, para a $\beta$-galactosidase, e $24 \%$ para a $\alpha$-galactosidase (Fig. 3 ). Apesar da carência de informações sobre os efeitos de sais in vitro nas atividades galactosidásicas, Thiyagarajah et al. (1996) mostraram que várias enzimas de paredes celulares, incluindo-se as galactosidases de folhas da halófita Suaeda maritima e das glicófitas Vigna radiata e Cicer arietnum, quando submetidas a concentrações crescentes de $\mathrm{NaCl}$, in vitro, praticamente não foram afetadas pelo sal até a concentração de $1.000 \mathrm{mM}$. Esta discrepância dos resultados pode ser atribuída às diferenças em tecidos e espécies utilizadas.

Nos experimentos in vivo (Fig. 2), o $\mathrm{NaCl}$ na concentração de $100 \mathrm{mM}$, ao contrário do observado in vitro nesta mesma concentração (Fig. 3), inibiu as atividades $\alpha$-e $\beta$-galactosidásicas nos estádios iniciais de desenvolvimento (Fig. 2A, C) e estimulou essas atividades nos estádios finais. Além disso, a forte redução nos valores das atividades $\alpha$ - e $\beta$-galactosidásicas, pela salinidade, observada em função dos vários estádios de desenvolvimento (Fig. 2B, D), sugerem que houve um retardamento na ativação dessas enzimas, $\mathrm{e}$ consequentemente, em suas atividades. Respostas de enzimas à ação de sais, in vivo e in vitro já foram observadas (GomesFilho \& Prisco 1978; Enéas-Filho et al. 1995) e as diferenças são explicadas com base no microambiente da enzima, in vitro, o qual é diferente do encontrado in vivo (Greenway
\& Osmond 1972). As interações dos íons com as enzimas, in vitro, se fazem de forma artificial, pois eles interagem diretamente com as proteínas em solução, enquanto que, in vivo, as células podem regular o meio iônico do citosol, via compartimentalização, evitando o contato direto das enzimas com os altos níveis de sal (Bray et al., 2000).

Tendo em vista que o alongamento celular é o processo fisiológico mais sensível aos estresses hídrico e salino (Hsiao \& Acevedo 1974), os resultados aqui apresentados sugerem que a inibição do crescimento dos caules ao longo do desenvolvimento das plântulas e do tempo de semeadura (Fig. 1) pode estar relacionada com a inibição e o retardamento das atividades galactosidásicas (Fig. 2). Essas enzimas, como se sabe, atuam sobre os componentes da parede celular, podendo promover seu afrouxamento e daí o alongamento celular (Buckeridge \& Dietrich 1996; Alcântara et al. 1999; Barnavon et al.2000). Apesar disso, o aumento nas atividades dessas enzimas, a partir do ED V, não foi capaz de fazer com que o comprimento dos caules no tratamento salino, superasse o das condições controle. Isso pode ter ocorrido devido a outros fatores envolvidos no processo de crescimento e desenvolvimento das plântulas. Estes resultados sugerem, ainda, que essas enzimas tiveram suas sínteses e/ ou ativações inibidas ou retardadas pela salinidade, especialmente durante os estádios iniciais de desenvolvimento das plântulas (até o ED V). Corroborando com isso, está a redução no teor de proteínas causado pela salinidade, nos primeiros estádios de desenvolvimento (Fig. 2E).

Para uma melhor compreensão dos resultados apresentados na Fig. 2 em que nos estádios finais de desenvolvimento as atividades galactosidásicas de parede celular foram maiores no tratamento salino do que no controle, os níveis de atividades dessas enzimas foram determinados em hipocótilos e epicótilos de plântulas no ED VIII (Fig. 4). No tratamento salino, enquanto a atividade $\alpha$-galactosidásica foi igual àquela nos hipocótilos do tratamento controle, a atividade $\beta$-galactosidásica foi $36,4 \%$ maior que aquela do controle. Quando extraídas de epicótilos, as atividades $\alpha$ - e $\beta$-galactosidásicas foram 77,8 e $92,8 \%$ maiores no tratamento salino do que no controle, respectivamente. Com isso, comprova-se que a diferença entre os níveis de atividades das enzimas, no tratamento salino em relação ao controle, foi maior em epicótilos do que em hipocótilos, sugerindo que os epicótilos foram os grandes responsáveis pela maior atividade galactosidásica dos caules nos estádios finais de desenvolvimento da plântula. É comum que na região apical do caule (epicótilo) haja uma maior taxa de alongamento celular, seja por suprimento hormonal, por fototropismo, ou por outros fatores. E o fato das galactosidases poderem atuar no processo de alongamento da célula sugere que a expressão gênica dessas enzimas nessa região tenha sido aumentada por alguns destes fatores. Isso pode justificar o fato dos epicótilos serem os principais responsáveis pelo crescimento dos caules nos estádios finais.

Do exposto, conclui-se que a salinidade, tanto inibiu como retardou o crescimento dos caules das plântulas 


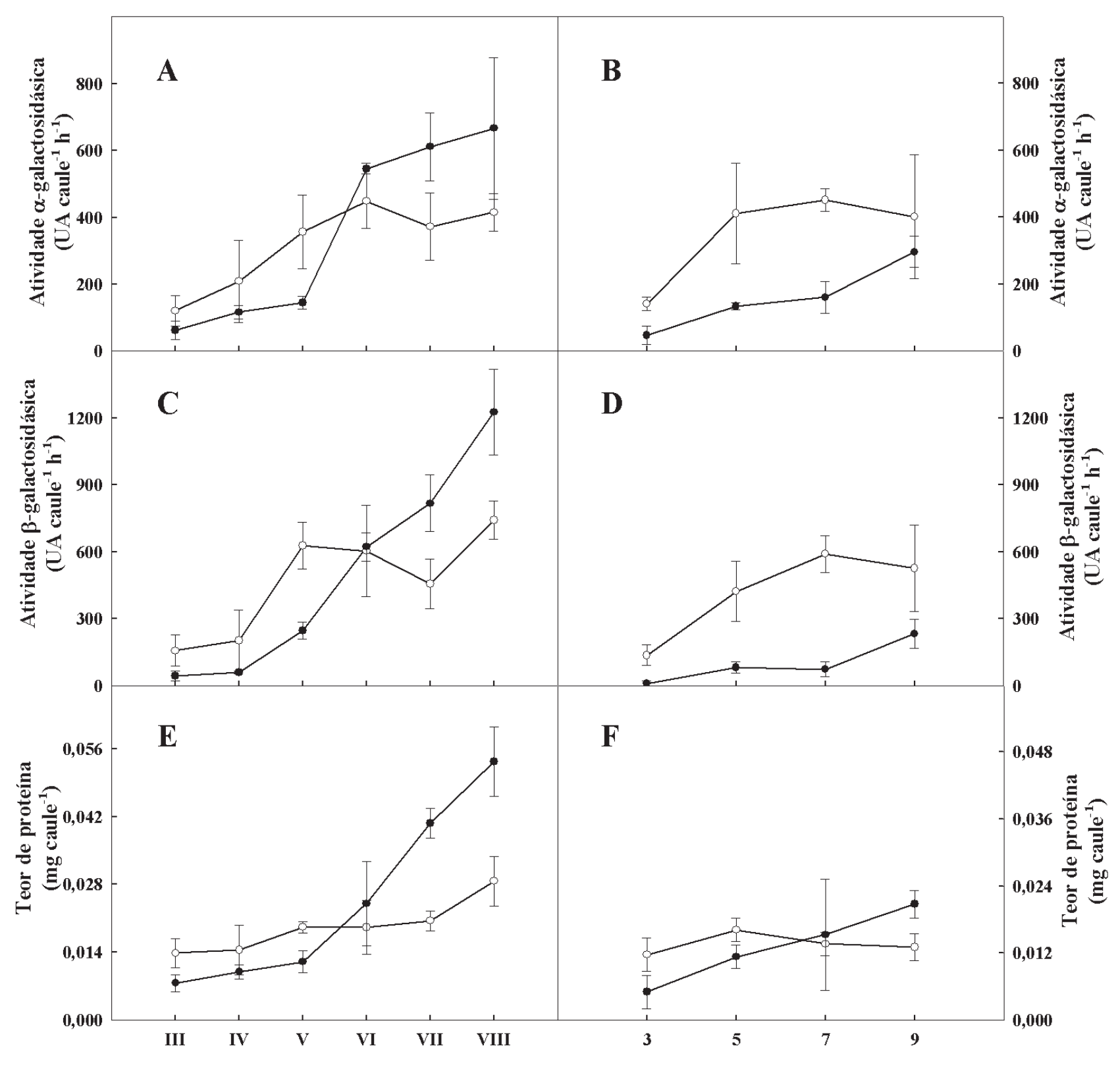

Estádios de desenvolvimento

Dias após a semeadura

Figura 2. Atividades das $\alpha$ - (A e B) e $\beta$-galactosidases ( $\mathrm{C}$ e D) e teor de proteínas extraídas (E e F) da parede celular de caules de plântulas de feijão-de-corda [Vigna unguiculata (L.) Walp.] cultivar Pitiúba em função do estádio de desenvolvimento (A, C e E) e do tempo após a semeadura (B, D e F) em água destilada (tratamento controle, o-o) e em solução de $\mathrm{NaCl}$ a $100 \mathrm{mM}$ (tratamento salino, •-•).

estressadas, sendo esta inibição mais visível nos estádios iniciais de desenvolvimento (até o ED VI) e que houve uma boa correlação entre o crescimento dos caules e o desenvolvimento das atividades galactosidásicas na parede celular, especialmente nos estádios iniciais de desenvolvimento.

\section{Agradecimentos}

À Coordenação de Aperfeiçoamento de Pessoal de Nível Superior (CAPES) e ao Conselho Nacional de Desenvolvimento Científico e Tecnológico (CNPq), pelas bolsas concedidas aos autores, e à Fundação de Apoio ao Desenvolvimento Científico e Tecnológico (FUNCAP) e ao Instituto Nacional de Ciência e Tecnologia em Salinidade (INCTSal/CNPq), pelo suporte financeiro. Ao Professor Emérito José Tarquínio Prisco pela constante orientação na realização deste trabalho.

\section{Referências bibliográficas}

Alcântara, P.H.N.; Dietrich, S.M.C.; Buckeridge, M.S. 1999. Xyloglucan mobilisation and purification of a (XLLG/XLXG) specific $\beta$-galac- 


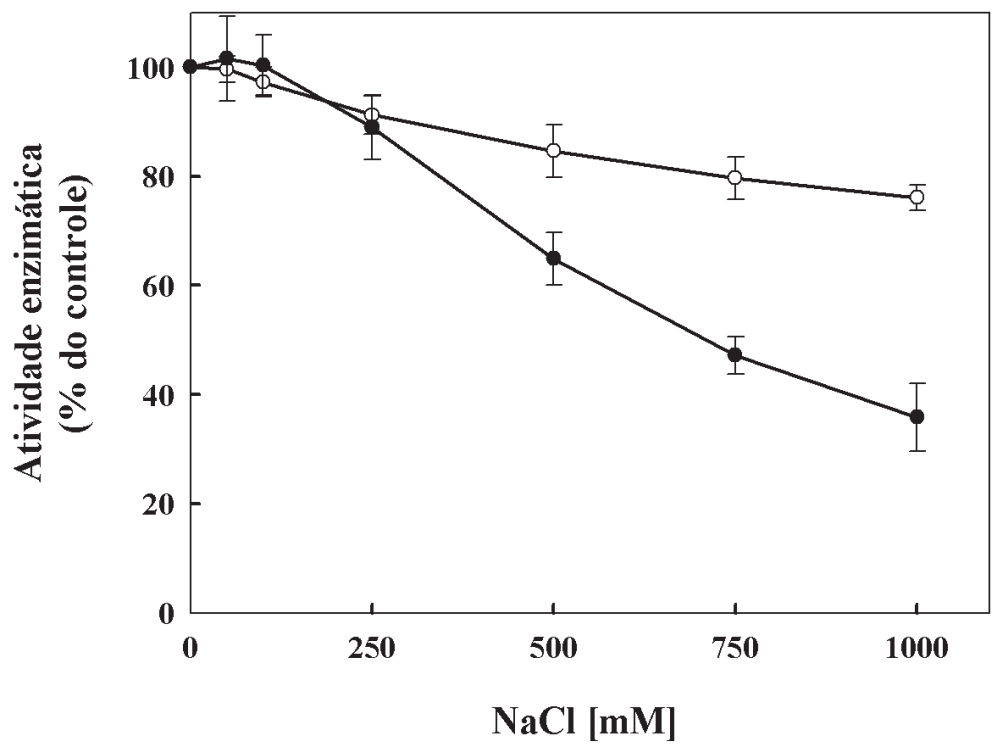

Figura 3. Atividade das $\alpha$ - $(\mathrm{o}-\mathrm{o})$ e $\beta$-galactosidases $(\bullet-\bullet)$ de parede celular extraídas de caules de plântulas de feijão-de-corda [Vigna unguiculata (L.) Walp] cultivar Pitiúba em função de quantidades crescentes de $\mathrm{NaCl}$ no meio de reação. Foram usadas plântulas do tratamento controle, no estádio de desenvolvimento VIII; para efeito de atividade enzimática considerou-se como controle a atividade do extrato sem $\mathrm{NaCl}$ no meio de reação.

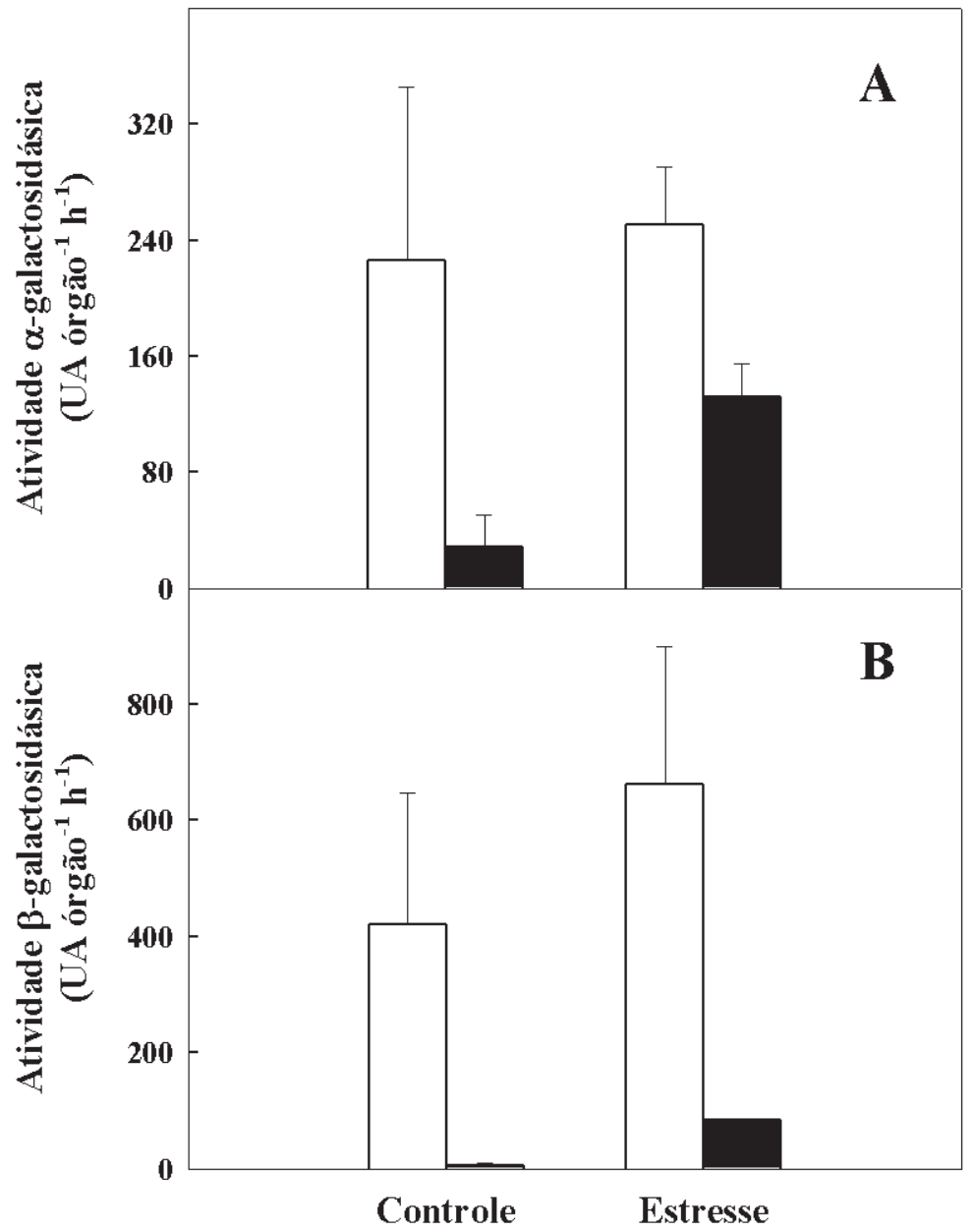

Figura 4. Atividade das $\alpha$ - (A) e $\beta$-galactosidases (B) extraídas de paredes celulares de hipocótilos ( $\square$ ) e epicótilos ( $\square$ ) de plântulas de feijão-de-corda [Vigna unguiculata (L.) Walp.] cultivar Pitiúba cultivadas em água destilada (tratamento controle) e em solução de $\mathrm{NaCl}$ a $100 \mathrm{mM}$ (tratamento salino). Foram utilizados caules de plântulas no estádio de desenvolvimento VIII. 
tosidase from cotyledons of Copaifera langsdorffi. Plant Physiology Biochemistry 37: 653-663.

Barnavon, L.; Doco, T.; Terrier, N.; Agcorges, A.; Romicu, C. \& Pellerin, P. 2000 . Analysis of cell wall neutral sugar composition, $\beta$-galactosidase activity and a related cDNA clone throughout the development of Vitis vinifera grape berries. Plant Physiology Biochemistry 38: 289-300.

Bewley, J.D.; Black, M. 1994. Seeds: Physiology of development and germination. New York, Plenum Press.

Bradford, M.M. 1976. A rapid and sensitive method for the quantification of microgram quantities of protein utilizing the principle of proteindye binding. Analitical Biochemistry 72: 248-254.

Bray, E.A.; Bayley-Serres, J. \& Weretilnyk, E. 2000. Responses to abiotic stresses. Pp. 1158-1203. In: Buchanan, B.B.; Gruissem, W. \& Jones, R.L. Biochemistry \& Molecular Biology of Plants. Maryland, American Society of Plant Physiologists.

Buckeridge, M.S. \& Dietrich, S.M.C. 1996. Mobilisation of the raffinose family oligosaccharides and galactomannan in germinating seeds of Sesbania marginata benth. (Leguminosae - Faboideae). Plant Science 117: 33-43.

Chartzoulakis, K.S.; Loupassaki, M.; Bertaky, M. \& Androulakis, I. 2002. Effects of $\mathrm{NaCl}$ on growth, ion content and $\mathrm{CO}_{2}$ assimilation rate of six olive cultivars. Scientia Horticulture 96: 235-247.

Chen, K.; Hu, G.; Keutgen, N.; Janssens, M. J. J. \& Lens, F. 1999. Effects of $\mathrm{NaCl}$ salinity and $\mathrm{CO}_{2}$ enrichment on pepino (Solanum muricatum Ait.) I. growth and yield. Scientia Horticulturae 81: 25-41.

Chinnusamy, V.; Jagendorf, A. \& Zhu, J.K. 2005. Understanding and improving salt tolerance in plants. Crop Science 45: 437-448.

Corchete, M.P. \& Guerra, H. 1986. Effect of $\mathrm{NaCl}$ and polyethylene glycol on solute content and glycosidase activities during germination of lentil seeds. Plant cell and environment 9: 589-593.

Dey, P.M. \& Pridham, J.B. 1969. Purification and properties of $\alpha$-galactosidases from Vicia faba seeds. Journal of Biochemistry 113: 49-55.

Enéas-Filho, J.; Oliveira-Neto, O.B.; Prisco, J.T.; Gomes-Filho, E. \& Nogueira, C.M. 1995. Effects of salinity in vivo and in vitro on cotyledonary galactosidases from Vigna unguiculata (L.) Walp. during germination and seedling establishment. Revista Brasileira de Fisiologia Vegetal 7: 135-142.

Gheyi, H.R. 2000. Problema de salinidade na agricultura irrigada. Pp. 329-346. In: Oliveira, T.S.; Assis Júnior, R.N.; Romero, R.E.; Silva, J.R.C. Agricultura, sustentabilidade e o semi-árido. Fortaleza, CE: DCS/UFC

Gomes-Filho, E.; Prisco, J.T. 1978. Effects of $\mathrm{NaCl}$ salinity in vivo and in vitro on the proteolytic activity of Vigna sinensis (L.) Savi cotiledons during germination. Revista Brasileira de Botânica 1: 83-88.

Gómez, L.D.; Casano, L.M.; Braga, M.R.; Buckeridge, M.S. 1995. Changes in extracellular $\beta$-galactosidase and protease activities during bean hypocotyls growth. Revista Brasileira de Fisiologia Vegetal 7: 1-6.

Gonzales-Murua, C.; Sánchez-Días, M.; Aparicio-Tejo, P.; Muñoz-Rueda, A. \& Reid, J.S.G. 1985. The effect of $\mathrm{NaCl}$ and water stress on germination and $\alpha$-galactosidase activity in germinated seeds of Medicago sativa, Trifolium repens and T. brachycalycinum. Journal of Plant Physiology 119: 317-326.

Granjeiro, P.A.; Ferreira, C.V.; Cavagis, A.D.M; Granjeiro, J.M. \& Ayoama, H. 2003. Essencial sulfhydryl groups in the active site of castor bean (Ricinus communis) seed acid phosphatase. Plant Science 164: 629-633.
Greenway, H.; Osmond, C.B. 1972. Salt responses of enzymes from species differing in salt tolerance. Plant Physiology 44: 1031-1034.

Hsiao, T.C.; Acevedo, E. 1974. Plant responses to water deficits, water-use effciency, and drought resistance. Agricultural Physiology 14: 59-84.

Jolivet, Y.; Pireaux, J.C. \& Dizengremel, P. 1990. Changes in properties of barley leaf mitochondria isolated from $\mathrm{NaCl}$ - treated plants. Plant Physiology 94: 641-646.

Kanfer, J.N.; Petrovich, R. \& Mumford, R.A. 1973. Purification of $\alpha$ - e $\beta$-galactosidases by affinity chromatography. Analitical Biochemistry 55: 301-305.

Kurban, H.; Saneoka, H.; Nehira, K.; Adilla, R. \& Fujita, K. 1998. Effect of salinity on growth and accumulation of organic and inorganic solutes in the leguminous plants Alhagi pseudoalhagi and Vigna radiata. Soil Science and Plant Nutrition 44: 589-597.

Lovato, M.B.; Lemos-Filho, J.P. \& Martins, P.S. 1999. Growth responses of Stylosanthes humilis (Fabaceae) populations to saline stress. Environment and Experimental Botany 41: 145-153.

Lutts, S.; Kinet, J.M. \& Bouharmont, J. 1995. Changes in plant response to $\mathrm{NaCl}$ during development of rice (Oryza sativa L.) varieties differing in salinity resistance. Journal of Experimental Botany 46: 1843-1852.

Martínez-Ballesta, M.C.; Martínez, V. \& Carvajal, M. 2004. Osmotic adjustment, water relations and gas exchange in pepper plants grown under $\mathrm{NaCl}$ or $\mathrm{KCl}$. Environmental and Experimental Botany 52: 161-174.

Molina, L.; Constantinescu, F.; Michel, L.; Reimmann, C.; Duffy, B. \& Défago, G. 2003. Degradation of pathogen quorum-sensing molecules by soil bacteria: a preventive and curative biological control mechanism. FEMS Microbiology Ecology 45: 71-81.

Parida, A.K. \& Das, A.B. 2005. Salt tolerance and salinity effects on plants: a review. Ecotoxicology and Environmental Safety 60: 324-349.

Ruiz, D.; Martinez, V. \& Cerdá, A. 1999. Demarcating specific ion $(\mathrm{NaCl}$, $\mathrm{Cl}, \mathrm{Na}^{+}$) and osmotic effects in the response of two citrus rootstocks to salinity. Scientia Horticulturae 80: 213-224.

Seara, J.; Nicolás, G. \& Labrador, E. 1988. Autolysis of the cell wall. Its possible role endogenous and IAA-induced growth in epicotyls of Cicer arietnum. Physiologia Plantarum 72: 762-774.

Sosa, L.; Llanes, A.; Reinoso, H.; Reginato, M. \& Luna, V. 2005. Osmotic and specific ín effects on the germination of Prosopis strombulifera. Annals of Botany 96: 261-267.

Sousa, M.F.; Campos, F.A.P.; Prisco, J.T.; Enéas-Filho, J. \& Gomes-Filho, E. 2004. Growth and protein pattern in cowpea seedlings subjected to salinity. Biologia Plantarum 47: 341-346.

Taiz, L.; Zeiger, E. 2004. Fisiologia Vegetal. Porto Alegre, Artmed.

Tester, M.; Davenport, R. 2003. $\mathrm{Na}^{+}$tolerance and $\mathrm{Na}^{+}$transport in higher plants. Annals of Botany 91: 503-527.

Thiyagarajah, M.; Fry, S.C. \& Yco, A.R. 1996. In vitro salt tolerance of cell wall enzymes from halophytes and glicophytes. Journal of Experimental Botany 47: 1717-1724

Wang, D.; Shannon, M.C. \& Grieve, C.M. 2001. Salinity reduces radiation absorption and use efficiency in soybean. Field Crops Research 69:267-277.

Zeng, L.; Shannon, M.C. \& Lesch, S.M. 2001. Timing of salinity stress affects rice growth and yield components. Agricultural Water Management 48: 191-206.

Zhu, J.-K. 2001. Plant salt tolerance. Trends in Plant Science 6: 66-71. 